\title{
Factors associated with survival in adult patients with traumatic arrest: a retrospective cohort study from US trauma centers
}

\author{
Abdel-Badih Ariss ${ }^{1}$, Rana Bachir ${ }^{1}$ and Mazen El Sayed ${ }^{1,2^{*}}$
}

\begin{abstract}
Background: Traumatic arrests increasingly affect young adults worldwide with low reported survival rates. This study examines factors associated with survival (to hospital discharge) in traumatic arrests transported to US trauma centers.

Methods: This retrospective cohort study used the US National Trauma Databank 2015 dataset and included patients who presented to trauma centers with "no signs of life". Univariate and bivariate analyses were done. Factors associated with survival were identified using multivariate regression analyses.

Results: The study included 5980 patients with traumatic arrests. Only 664 patients (11.1\%) survived to hospital discharge. Patients were predominantly in age group 16-64 (84.6\%), were mostly males (77.8\%) and white (55.1\%). Most were admitted to Level I (55.5\%) or Level II trauma centers (31.6\%). Injuries were mostly blunt (56.7\%) or penetrating (39.3\%). The median of the injury severity score (ISS) was 19 (interquartile range [IQR]: 9-30). Factors associated with decreased survival included: Age group $\geq 65$ (Ref: 16-24), male gender, self-inflicted and other or undetermined types of injuries (Ref: assault), injuries to head and neck, injuries to torso and ISS $\geq 16$ (Ref: < 16) and ED thoracotomy. While factors associated with increased survival included: All injury mechanisms (with the exception of motor vehicle transportation) (Ref: firearm), injuries to extremities or spine and back and all methods of coverage (Ref: self-pay).

Conclusion: Patients with traumatic arrests have poor outcomes with only $11.1 \%$ surviving to hospital discharge. Factors associated with survival in traumatic arrests were identified. These findings are important for devising injury prevention strategies and help guide trauma management protocols to improve outcomes in traumatic arrests.
\end{abstract}

\footnotetext{
* Correspondence: melsayed@aub.edu.lb

'Department of Emergency Medicine, American University of Beirut Medical

Center, Riad El Solh, P.O. Box - 11-0236, Beirut 1107 2020, Lebanon

${ }^{2}$ Emergency Medical Services and Prehospital Care Program, American

University of Beirut Medical Center, Beirut, Lebanon
}

(c) The Author(s). 2021 Open Access This article is licensed under a Creative Commons Attribution 4.0 International License, which permits use, sharing, adaptation, distribution and reproduction in any medium or format, as long as you give appropriate credit to the original author(s) and the source, provide a link to the Creative Commons licence, and indicate if changes were made. The images or other third party material in this article are included in the article's Creative Commons licence, unless indicated otherwise in a credit line to the material. If material is not included in the article's Creative Commons licence and your intended use is not permitted by statutory regulation or exceeds the permitted use, you will need to obtain permission directly from the copyright holder. To view a copy of this licence, visit http://creativecommons.org/licenses/by/4.0/ The Creative Commons Public Domain Dedication waiver (http://creativecommons.org/publicdomain/zero/1.0/) applies to the data made available in this article, unless otherwise stated in a credit line to the data. 
Level of evidence: Level III.

Keywords: Traumatic arrest, Survival, Outcome, Injury, Resuscitation

\section{Background}

Traumatic arrests (TA) or traumatic deaths are increasingly affecting the young population worldwide. According to a 2014 report by the World Health Organization (WHO), more than 5 million individuals die from injuries each year which accounts for approximately $9 \%$ of global deaths [1]. Main causes of fatal injuries are road traffic injuries, homicide and suicide [1]. TA has also increased in the US by $22.8 \%$ between the years 2000 and 2010, affecting mainly young adults [2]. As a result, traumatic fatalities compete with cancer and heart related mortality in the young population [2].

Prior studies that examined traumatic arrests have reported very low survival rates ranging from 1.5 to $12.5 \%$ [3-5]. Guidelines to withhold resuscitative measures specific for traumatic arrests have also been proposed in previous studies and by major organizations such as National Association of Emergency Medical Services Physicians and the American College of Surgeons Committee on Trauma (NAEMSP/ACS-COT) because of the futility of resuscitative measures for this condition $[6,7]$. Survival has however been increasing with the improvement of medical interventions as well as the establishment of trauma systems [8,9].

Previously identified factors that may contribute to increased survival in traumatic arrests include emergency department thoracotomy [9], presence of VF on admission [10, 11], witnessed TA [11], pre-hospital chest decompression [12], admission to trauma center [5, 13], lower injury severity score (ISS), high Glasgow Coma score, Caucasian race and higher systolic blood pressure (SBP) [5].

With evolving trauma care, improved survival is expected and factors associated with survival might change. This study used the 2015 dataset from the US National Trauma Databank (1) to examine characteristics and outcomes of patients suffering from traumatic arrests and (2) to identify factors associated with survival in traumatic arrests victims who were treated in US trauma centers.

\section{Methods}

\section{Study design}

This retrospective cohort study used the 2015 public release dataset of the National Trauma Data Bank (collected in 2015 and released in 2017).

An Institutional Review Board Exemption was obtained at the American University Of Beirut to use this de-identified dataset.

\section{Study setting}

The National Trauma Database represents the largest U.S trauma data registry, is maintained by The American College of Surgeons Committee on Trauma and collects information from more than 900 facilities across the U.S. This registry includes patients who sustained one or more injuries that resulted in death, transfer or admission to a hospital and who have a trauma related diagnosis code (ICD-9 CM (800-959.9) or ICD-10 CM (S00-S99, T07, T14, T20-T28, T30-T32 and T79.A1T79.A9) except cases with ICD-9CM codes 905-909.9, 910-924.9 and 930-939.9 and ICD-10CM codes (S00, S10, S20, S30, S40, S50, S60, S70, S80, S90) [14].

The variables included in the database include patient related information (demographic, coverage, outcome), event related information (injury severity, characteristics, diagnosis, pre-hospital, ED and hospital information) in addition to other information related to quality assurance and process of care measures. The injury severity score was categorized into two groups $(\leq 15, \geq 16)$ to classify all patients as having minor or major trauma [15].

\section{Study population}

The 2015 NTDB data set contains 917,865 patients of which 8026 presented to the ED with "no signs of life" defined as "having none of the following: organized EKG activity, pupillary responses, spontaneous respiratory attempts or movement, and unassisted blood pressure" [16]. These patients were assumed to have CPR in progress on admission to the ED as per the NTDB dictionary and were considered to have sustained a traumatic arrest. Only adult patients were included and they were defined similarly to previous studies as those aged 16 years and above [17]. Patients were excluded if age was not recorded $(n=443)$, if they were transferred from other hospitals (recorded as inter-facility transfer; $n=$ 521) and if outcome was unknown (ED discharge disposition recorded as: not known/recorded $(n=280)$, not applicable $(n=92)$, home with services $(n=9)$, home without services $(n=173)$, left against medical advice $(n=9)$, transferred to another hospital $(n=97)$, other (jail, institution care facility, mental health; $n=$ 6) or if hospital discharge disposition was recorded as unknown; $n=1$ ).

\section{Statistical analysis}

Data were analyzed using the Statistical Package for the Social Sciences (SPSS, version 24). Descriptive analysis 
was initially performed. Categorical variables were presented using frequencies and percentages whereas the continuous variables were summarized using the mean \pm standard deviation (SD), median and interquartile range (IQR).

Recoding was done for some variables due to the low frequencies of their categories. For example, the nature of injury which was originally composed of 12 categories (amputations, blood vessels, burns, crush, dislocation, fractures, internal organ, nerves, open wounds, sprains and strains, system wide and late effects, unspecified) was grouped into 7 categories with other nature of injury created by combining the following categories together: amputations, burns, crush, nerves, sprains and strains, system wide and late effects.

Depending on the cell count, Pearson's Chi-Square or Fishers' exact tests were used to compare the proportions of all categorical variables in terms of the outcome variable (survived: yes/no). The descriptive analysis revealed that more than $10 \%$ of the following variables (ethnicity: 11.0\%, whether patient used alcohol: 13.5\%, whether patient used drug: 11.1\%) were categorized as being not known/not recorded. To provide accurate estimates, missing data were handled through multiple imputations. Five imputed datasets were generated. An automatic imputation method was used. This option automatically chooses an imputation method based on a scan of the data set.

A multivariate logistic regression using a forward selection procedure was conducted to find the best model that explains the association between hospital survival and all patients' demographic and clinical characteristics. More specifically, a multivariate analysis was performed by taking into consideration all factors deemed to be clinically or statistically significant [age, gender, race, hospital teaching status, geographic region for the hospital, comorbidity, ICD-9-CM mechanism of injury ECode, indication of the type (nature) of trauma produced by an injury, injury intentionality as defined by the CDC injury intentionality matrix, location where injury occurred, whether patient used alcohol, whether patient used drug, the patient's primary method of payment, mode of transportation, the injury severity score reflecting the patient's injuries directly submitted by the facility regardless of the method of calculation, ICD-9 body region as defined by the Barell injury diagnosis matrix (blood vessels, dislocation, fractures, internal organ, open wounds, unspecified, other), nature of injury as defined by the Barell injury diagnosis matrix (extremities, head and neck, spine and back, torso, unclassifiable by site), ED Thoracotomy procedure. $p$ value of $\leq 0.05$ was used to denote statistical significance. The c-statistic of

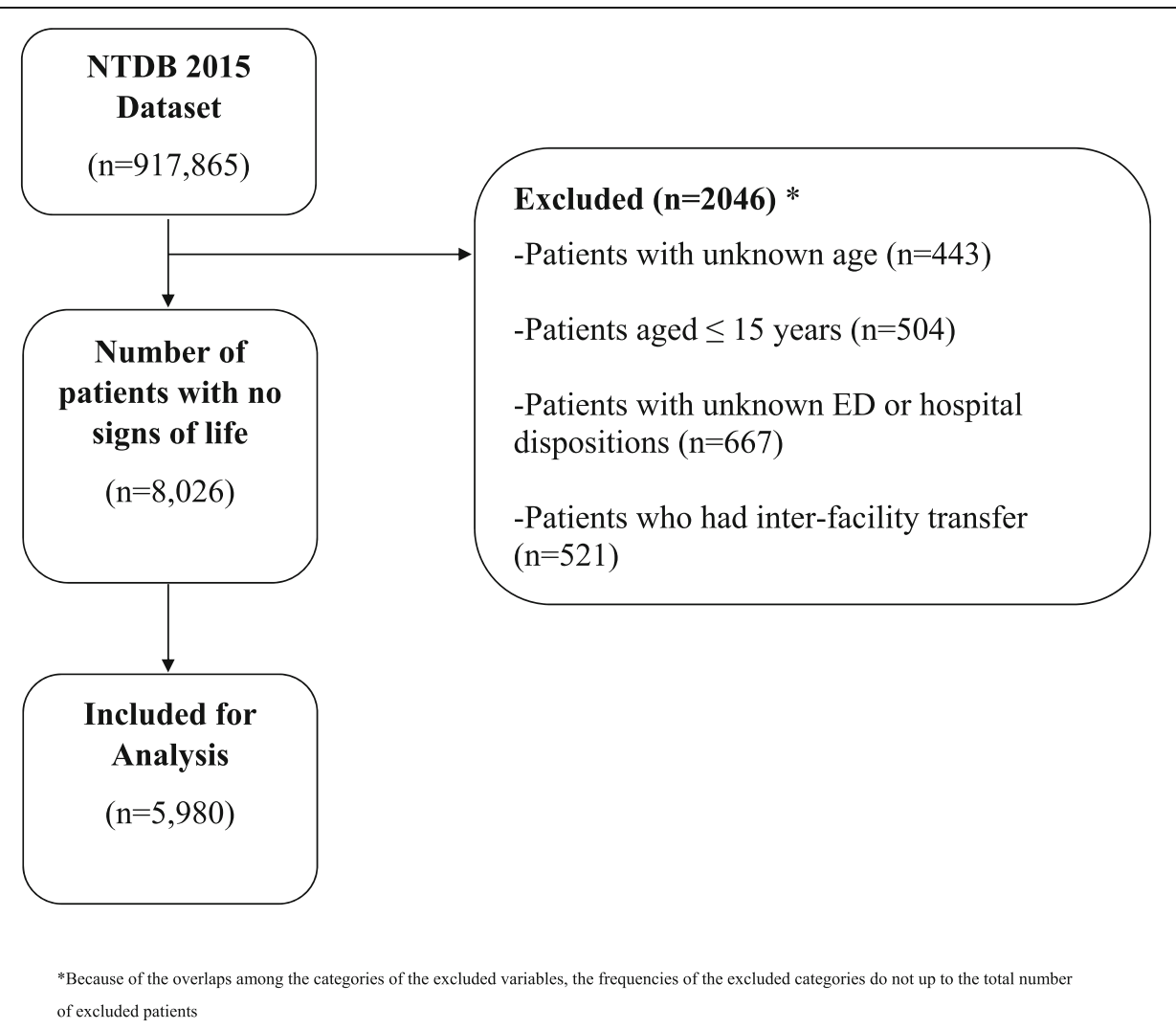

Fig. 1 Study population 
the regression model (area under the curve $=0.934 ; p$ value $<0.001 ; 95 \%$ CI $0.924-0.943)$ indicated an outstanding discrimination between the two categories of the outcome (died/survived). There was no multicollinearity problem in the regression model since the variance inflation factors of all independent variables were less than 10; these ranged from 1.023 to 4.257 .

\section{Results}

A total of 5980 patients were included in the study (Fig. 1). Only 664 patients (11.1\%) survived to hospital discharge. Patients were predominantly in the age group 16-64 (84.6\%) with a median age of 39 years (IQR $=26-$ 56) (Table 1). Patients were mostly males $(77.8 \%)$ and white (55.1\%). Receiving hospitals were mainly University hospitals (47.7\%) and community hospitals (38.9\%). Most patients were admitted to Level 1 (55.5\%) or Level 2 Trauma Centers (31.6\%). Hospitals located in the South region of the U.S received the largest number of patients with traumatic arrests (46.8\%) (Table 1). Selfpay was the most common primary method of payment (38.5\%) followed by private insurances (25.3\%). Most patients were transported by ground ambulance (83.9\%) and most had no reported comorbidity (70.7\%). Injuries were mostly blunt (56.7\%) followed by penetrating (39.3\%). Most injuries were unintentional (58.2\%) followed by assault (29.4\%). The leading mechanism of injury was MVT (38.4\%) followed by Firearm (34.4\%). Types of reported injuries included mainly fractures (59.0\%), internal organ damage (56.2\%) and open wounds (50.6\%). The torso and the head and neck were the most commonly affected regions $(59.4 \%$ and $52.6 \%$, respectively). Median ISS was 19 (IQR 9-30) with more than half of the patients having severe injury (57.1\%). Thoracotomy was performed on (10.1\%) of patients. (Table 2).

Results of the logistic regression analysis revealed the following (Table 3): Demographic characteristics that were associated with decreased odds of survival included age group $\geq 65(\mathrm{OR}=0.612,95 \% \mathrm{CI}=0.426-0.878)$ and male gender $(\mathrm{OR}=0.63,95 \% \mathrm{CI}=0.49-0.811)$. Among facility related characteristics, location of hospital in South was positively associated with survival (OR = 2.055, 95\% CI $=1.444-2.924$ ) (reference Northeast). Reported comorbidity $(\mathrm{OR}=3.201,95 \% \mathrm{CI}=2.535-4.042)$, alcohol use $(\mathrm{OR}=2.836,95 \% \mathrm{CI}=2.053-3.917)$ or drug use $(\mathrm{OR}=5.17,95 \% \mathrm{CI}=3.695-7.234)$ were associated with increased survival. All injury mechanisms (with the exception of MVT) were significantly associated with increased odds of survival when compared to injury by firearm. Additionally, all methods of coverage were positively associated with survival when compared to selfpay.
Injury related factors associated with survival were also identified. Self-inflicted and other or undetermined types of injuries were associated with decreased survival when compared to assault type of injuries. Presence of specific types of injuries such as fractures $(\mathrm{OR}=2.008,95 \% \mathrm{CI}=$ 1.526-2.643), internal organ damage $(\mathrm{OR}=1.958,95 \%$ $\mathrm{CI}=1.476-2.598$ ), and other nature of injury $-\mathrm{a}$ variable that was created by combining some injuries together$(\mathrm{OR}=2.336,95 \% \mathrm{CI}=1.506-3.624)$ were all associated with higher odds of survival. Patients who had unspecified $(\mathrm{OR}=0.639,95 \% \mathrm{CI}=0.42-0.972)$ injuries were less likely to survive. Patients who had injuries in their extremities $(\mathrm{OR}=1.471,95 \% \mathrm{CI}=1.152-1.879)$ or spine and back $(\mathrm{OR}=1.652,95 \% \mathrm{CI}=1.205-2.264)$ were more likely to survive, whereas those who had injuries in their head and neck $(\mathrm{OR}=0.405,95 \% \mathrm{CI}=0.314-0.523)$ or torso $(\mathrm{OR}=0.473,95 \% \mathrm{CI}=0.356-0.629)$, or in unclassifiable site $(\mathrm{OR}=0.273,95 \% \mathrm{CI}=0.154-0.483)$ had poor outcome. Injury severity score $\geq 16$ was associated with decreased odds of survival from traumatic arrest $(\mathrm{OR}=$ $0.092,95 \% \mathrm{CI}=0.068-0.125)$. Finally, ED thoracotomy was as well associated with a lower odds of survival $(\mathrm{OR}=0.334,95 \% \mathrm{CI}=0.169-0.662)$.

\section{Discussion}

Research involving traumatic arrests is rare. This study examined outcomes of patients with traumatic arrests treated in US trauma centers and identified factors associated with survival in this population using the largest trauma database in the US. These factors have not been previously described in the literature.

The overall survival to hospital discharge among patients with traumatic arrests was $11.1 \%$. This rate is slightly lower than the rate of $12.5 \%$ reported by Ahmed et al. [5] but higher than other survival rates reported in earlier studies $[13,18]$. Young, white and male individuals continue to be mostly affected by traumatic arrests $[1,5,11]$. Improved survival in traumatic arrests presenting to U.S hospitals has been previously attributed to the increasing frequency of emergency interventions such as ED thoracotomy and other procedures [19]. Variation in survival rates of patients with traumatic arrest is however mostly related to differences in study sample selections with most studies including in the denominator arrests that are not transported to hospitals [20]. Our study included only patients who were transported to a trauma center which might have overestimated the survival rate since patients declared dead on scene are not usually included in the NTDB registry.

There were several factors associated with increased survival in patients with traumatic arrests. Demographic factors positively associated with survival included age group (16-64) (compared to age $\geq 65$ ) and female gender. This differs from previous studies $[5,18,21]$ where 
Table 1 General characteristics of study population

\begin{tabular}{|c|c|c|}
\hline & Frequency & $\%$ \\
\hline & $(N=5980)$ & \\
\hline \multicolumn{3}{|l|}{ Age (years) } \\
\hline $16-64$ & 5062 & 84.6 \\
\hline$\geq 65$ & 918 & 15.4 \\
\hline \multicolumn{3}{|l|}{ Gender } \\
\hline Not known/not recorded & 3 & 0.0 \\
\hline Female & 1327 & 22.2 \\
\hline Male & 4650 & 77.8 \\
\hline \multicolumn{3}{|l|}{ Race } \\
\hline Not known/not recorded & 270 & 4.5 \\
\hline American Indian & 36 & 0.6 \\
\hline Asian & 96 & 1.6 \\
\hline Black or African American & 1876 & 31.4 \\
\hline Native Hawaiian or Other Pacific Islander & 18 & 0.3 \\
\hline White & 3292 & 55.1 \\
\hline Other race & 392 & 6.6 \\
\hline \multicolumn{3}{|l|}{ Hospital teaching status } \\
\hline Community & 2329 & 38.9 \\
\hline Non-teaching & 801 & 13.4 \\
\hline University & 2850 & 47.7 \\
\hline \multicolumn{3}{|l|}{ Trauma designation level } \\
\hline । & 3316 & 55.5 \\
\hline$\|$ & 1892 & 31.6 \\
\hline III & 580 & 9.7 \\
\hline IV & 44 & 0.7 \\
\hline Not applicable & 148 & 2.5 \\
\hline \multicolumn{3}{|l|}{ Geographic region for the hospital } \\
\hline NORTHEAST & 826 & 13.8 \\
\hline MIDWEST & 1179 & 19.7 \\
\hline SOUTH & 2800 & 46.8 \\
\hline WEST & 1129 & 18.9 \\
\hline NA & 46 & 0.8 \\
\hline \multicolumn{3}{|l|}{ The patient's primary method of payment } \\
\hline Not known/not recorded & 402 & 6.7 \\
\hline Medicaid & 728 & 12.2 \\
\hline Medicare & 655 & 11.0 \\
\hline Not billed (for any reason) & 61 & 1.0 \\
\hline Private/commercial insurance & 1512 & 25.3 \\
\hline Self-pay & 2302 & 38.5 \\
\hline Other government & 119 & 2.0 \\
\hline Other & 201 & 3.4 \\
\hline \multicolumn{3}{|l|}{ Mode of transportation } \\
\hline Not known/not recorded & 18 & 0.3 \\
\hline Ground ambulance & 5017 & 83.9 \\
\hline
\end{tabular}

Table 1 General characteristics of study population (Continued)

\begin{tabular}{lll}
\hline & Frequency & $\%$ \\
\cline { 2 - 3 } & $(\boldsymbol{N = 5 9 8 0 )}$ & \\
\hline Helicopter ambulance & 517 & 8.6 \\
Fixed-wing ambulance & 6 & 0.1 \\
Police & 79 & 1.3 \\
Public/private vehicle walk-in & 278 & 4.6 \\
Other & 65 & 1.1 \\
\hline
\end{tabular}

no similar associations were reported. Patients in the younger age are usually expected to have better odds of survival because of lower comorbidities. Female gender was significantly associated with survival in this population. A previous study did not identify significant association between female gender and outcomes in severely injured patients [22]. Age stratification was however done in that study to account for hormonal status. This finding in our study needs further examination with the potential role of other unmeasured confounders such as role of hormones based on age category (pre vs postmenopausal) and obesity etc.

Several injuries related characteristics that are relevant to treating physicians were also significantly associated with survival.

Type of trauma (blunt vs penetrating), which is mainly used for classification in trauma studies, was not significantly associated with survival similar to other previous studies $[5,18,23]$. This is in contrast with other studies that reported better outcomes with either penetrating [24] or with blunt injuries [25]. The sample used for our study was however heterogeneous and not restricted to a specific type which might explain this difference.

Additional classification by mechanisms of injuries revealed that most mechanisms were also positively associated with survival when compared to injury by firearm. While fall-related injuries were previously shown to be associated with increased survival when compared to MVT in blunt traumatic arrests $[24,26]$ this study is the first to examine all available mechanisms in traumatic arrests. The case fatality rate of firearm is usually much higher than any other mechanism of injury $[27,28]$ and is related to several factors including number of entrance wounds, range and site of entrance wounds and intentionality [22, 29]. The study findings highlight the need for better understanding of firearm related injuries and for developing preventive measures targeted to improve survival in this population.

Injury body region was also found to be significantly associated with survival: Injuries to vital locations such as head and neck, or torso were associated with poor outcomes. This was expected because of the risk of bleeding and hemorrhagic shock from damage to vital 
Table 2 Clinical characteristics and outcomes of patients

\begin{tabular}{lll}
\hline & Frequency & $\%$ \\
& &
\end{tabular}

Comorbidity

No

Yes

Type (nature) of trauma produced by an injury

Blunt

Burn

Other/unspecified

Penetrating

Missing $=322(5.4 \%)$

Injury intentionality

Assault

Self-inflicted

Undetermined

Unintentional

Other

Missing $=322(5.4 \%)$

Mechanism of injury

Cut/pierce

Fall

Firearm

MVT

Other specified and classifiable and other specified, not elsewhere classifiable

Struck by, against

Transport, other and unspecified

Others

Missing $=322(5.4 \%)$

Alcohol use

No

Yes

Drug use

No

Yes

Nature of injury

Amputations

Blood vessels

Burns

Crush

Dislocation

Fractures

Internal organ

Nerves

Open wounds
Table 2 Clinical characteristics and outcomes of patients (Continued)

\begin{tabular}{|c|c|c|}
\hline & Frequency & $\%$ \\
\hline & $\overline{(N=5980)}$ & \\
\hline Sprains and strains & 106 & 1.8 \\
\hline System wide and late effects & 91 & 1.5 \\
\hline Unspecified & 515 & 8.6 \\
\hline \multicolumn{3}{|l|}{ Body region of injury } \\
\hline Extremities & 2639 & 44.1 \\
\hline Head and neck & 3145 & 52.6 \\
\hline Spine and back & 877 & 14.7 \\
\hline Torso & 3554 & 59.4 \\
\hline Unclassifiable by site & 471 & 7.9 \\
\hline \multicolumn{3}{|l|}{ Injury severity score } \\
\hline$\leq 15$ & 2438 & 40.8 \\
\hline$\geq 16$ & 3415 & 57.1 \\
\hline Not known/not recorded & 127 & 2.1 \\
\hline \multicolumn{3}{|l|}{ ED thoracotomy } \\
\hline No & 5377 & 89.9 \\
\hline Yes & 603 & 10.1 \\
\hline \multicolumn{3}{|l|}{ ED disposition } \\
\hline Deceased/Expired & 4491 & 75.1 \\
\hline $\begin{array}{l}\text { Floor bed (general admission, } \\
\text { non-specialty unit bed) }\end{array}$ & 490 & 8.2 \\
\hline Intensive Care Unit (ICU) & 366 & 6.1 \\
\hline Observation unit (24 h stays) & 43 & 0.7 \\
\hline Operating room & 479 & 8.0 \\
\hline $\begin{array}{l}\text { Telemetry/step-down unit } \\
\text { (less acuity than ICU) }\end{array}$ & 111 & 1.9 \\
\hline \multicolumn{3}{|l|}{ Hospital disposition } \\
\hline Not applicable & 4491 & 75.1 \\
\hline Deceased/Expired & 496 & 8.3 \\
\hline $\begin{array}{l}\text { Discharged to home or self-care } \\
\text { (routine discharge) }\end{array}$ & 664 & 11.1 \\
\hline Transferred to other destination & 319 & 5.3 \\
\hline Left against medical advice or discontinued care & 10 & 0.2 \\
\hline
\end{tabular}

organs [30] and is in line with the ATLS approach to management of trauma patients by prioritizing management according to life-threatening injuries [31]. Other factors were also found to be positively associated with survival such as specific types of injuries (fractures, internal organ damage) in addition to alcohol or drug use. These are more likely related to reporting of such data elements in patients who survive after the initial resuscitation measures. Such patients are expected to have a more detailed documentation of minor injuries or better description of other elements contributing to the injury event. 
Table 3 Factors associated with survival in traumatic arrests

Age (years) (16-64)

$\geq 65$

Gender (Female)

Male

Geographic region for the hospital (NORTHEAST)

MIDWEST

SOUTH

WEST

Comorbidity (No)

Yes

Injury Intentionality as defined by the CDC Injury Intentionality Matrix (Assault)

Self-inflicted

Unintentional

Other and undetermined

ICD-9-CM Mechanism of Injury E-Code

(Firearm)

Cut/pierce

Fall

$\mathrm{MVT}^{\mathrm{a}}$

Other specified and classifiable and other specified, not elsewhere classifiable

Struck by, against

Transport, other and unspecified others ${ }^{b}$

Whether patient used alcohol (No)

Yes

Whether patient used drug (No)

Yes

The patient's primary method of payment (Self Pay)

Medicaid

Medicare

Private/commercial insurance

Other government

Other and not billed (for any reason)

Mode of transportation (Ground Ambulance)

Helicopter ambulance and fixed-wing ambulance

Public/private vehicle walk-in

Other and police

Nature of injury as defined by the Barell Injury

Diagnosis matrix fractures (No)

Yes

Nature of injury as defined by the Barell Injury

Diagnosis matrix Internal organ (No)

Yes
Odds ratio

1.480

2.055

0.199

1.203

5.240

7.317

1.152

2.544

7.211

3.082

2.342

15.649

$95 \% \mathrm{Cl}$

$p$ value

$0.426-0.878$

0.008

$0.490-0.811$

$<0.001$

$0.994-2.204$

0.054

$1.444-2.924$

$<0.001$

0.407

$<0.001$

$2.535-4.042$

$0.098-0.404$

$<0.001$

0.681-2.124

0.525

0.034-0.604

0.008

2.929-9.376

$<0.001$

3.871-13.831

$<0.001$

0.618-2.145

0.656

0.967-6.693

0.058

3.700-14.055

$<0.001$

1.432-6.634

0.004

$<0.001$

2.836

2.053-3.917

$<0.001$

5.170

2.902

3.512

6.973

2.881

$3.695-7.234$

$<0.001$

1.591-3.448

$<0.001$

1.863-4.552

$<0.001$

2.567-4.805

$<0.001$

3.466-14.029

$<0.001$

$1.692-4.906$

$<0.001$

1.103

1.213

0.766-1.589

0.599

9.077-26.978

$<0.001$

$0.364-4.050$

0.753

2.008

$1.526-2.643$

$<0.001$

1.958

$1.476-2.598$

$<0.001$ 
Table 3 Factors associated with survival in traumatic arrests (Continued)

\begin{tabular}{|c|c|c|c|}
\hline & Odds ratio & $95 \% \mathrm{Cl}$ & $p$ value \\
\hline \multicolumn{4}{|c|}{ Nature of injury as defined by the Barell Injury } \\
\hline \multicolumn{4}{|c|}{ Diagnosis matrix Unspecified (No) } \\
\hline Yes & 0.639 & $0.420-0.972$ & 0.036 \\
\hline \multicolumn{4}{|c|}{ Nature of injury as defined by the Barell Injury } \\
\hline \multicolumn{4}{|c|}{ Diagnosis matrix Other (No) } \\
\hline Yes & 2.336 & $1.506-3.624$ & $<0.001$ \\
\hline \multicolumn{4}{|c|}{ ICD-9 body region as defined by the Barell } \\
\hline \multicolumn{4}{|c|}{ Injury diagnosis matrix Extremities (No) } \\
\hline Yes & 1.471 & $1.152-1.879$ & 0.002 \\
\hline \multicolumn{4}{|c|}{ ICD-9 body region as defined by the Barell } \\
\hline \multicolumn{4}{|c|}{ Injury diagnosis matrix Head and Neck (No) } \\
\hline Yes & 0.405 & $0.314-0.523$ & $<0.001$ \\
\hline \multicolumn{4}{|c|}{ ICD-9 body region as defined by the Barell } \\
\hline \multicolumn{4}{|c|}{ Injury diagnosis matrix Spine and Back (No) } \\
\hline Yes & 1.652 & $1.205-2.264$ & 0.002 \\
\hline \multicolumn{4}{|c|}{ ICD-9 body region as defined by the Barell } \\
\hline \multicolumn{4}{|c|}{ Injury diagnosis matrix Torso (No) } \\
\hline Yes & 0.473 & $0.356-0.629$ & $<0.001$ \\
\hline \multicolumn{4}{|c|}{ ICD-9 body region as defined by the Barell } \\
\hline \multicolumn{4}{|c|}{ Injury diagnosis matrix Unclassifiable by site (No) } \\
\hline Yes & 0.273 & $0.154-0.483$ & $<0.001$ \\
\hline \multicolumn{4}{|c|}{$\begin{array}{l}\text { The Injury Severity Score reflecting the patient's } \\
\text { injuries directly submitted by the facility regardless } \\
\text { of the method of calculation }(\leq 15)\end{array}$} \\
\hline$\geq 16$ & 0.092 & $0.068-0.125$ & $<0.001$ \\
\hline \multicolumn{4}{|c|}{ ED thoracotomy (No) } \\
\hline Yes & 0.334 & $0.169-0.662$ & 0.002 \\
\hline
\end{tabular}

Variables that were included in the model are: age, gender, race, hospital teaching status, Geographic region for the hospital, comorbidity, ICD-9-CM Mechanism of Injury E-Code, Indication of the type (nature) of trauma produced by an injury, Injury Intentionality as defined by the CDC Injury Intentionality Matrix, Location where injury occurred, Whether patient used alcohol, Whether patient used drug, the patient's primary method of payment, Mode of Transportation, The Injury Severity Score reflecting the patient's injuries directly submitted by the facility regardless of the method of calculation, ICD-9 body region as defined by the Barell Injury Diagnosis Matrix (Blood vessels, Dislocation, Fractures, Internal organ, Open wounds, Unspecified, Other), Nature of injury as defined by the Barell Injury Diagnosis Matrix (Extremities, Head and Neck, Spine and Back, Torso, Unclassifiable by site), ED Thoracotomy

${ }^{\mathrm{a}} \mathrm{MVT}$ is the combination of the following variables: MVT Motorcyclist and MVT Occupant and MVT Other and MVT Pedal cyclist and MVT Pedestrian and MVT Unspecified

${ }^{b}$ Others is the combination of the following variables: Drowning/submersion and Fire/flame and Hot object/substance and Machinery and Pedal cyclist, other and Pedestrian, other and Natural/environmental, Bites and stings and Natural/environmental, Other and Overexertion and Poisoning and Suffocation

As expected an injury severity score (ISS $<16)$ was associated with higher survival in traumatic arrest patients. This finding is in line with previous studies $[5,13,18]$ and validates the need to incorporate ISS in outcome predictive models in not only trauma patients but also in traumatic arrests to avoid futility of extreme measures in resuscitation. ED thoracotomy was negatively associated with survival in our patient population. This is expected since the procedure is highly time dependent and considered as a last resort [19]. Thus, if not used in the appropriate population i.e. penetrating chest injuries, ED thoracotomy may be ineffective [9], as such its success rate misrepresented, especially in a heterogeneous population such as ours.

Our study also identified that hospital location in the South was associated with increased survival (reference Northeast) for patients with traumatic arrests. While improved outcomes in trauma patients have been previously linked to geographic clustering of trauma centers which are primarily located in the Northern area [32] and where patients benefit from the greatest access to trauma Level I and II centers within 45 and $60 \mathrm{~min}$ [33], our study did not identify such association. In our study sample, more 
hospitals were located in the South (47.2\%) than in the Northeast (13.9\%). Patients in the South were more likely to survive as compared to those in the Northeast (17.1\% vs. $13.4 \%)$ and additional stratification by mortality status revealed that disproportionate distribution of the participant hospitals may be responsible for this apparent survival differences between the two regions (Only two patients with firearm injury survived to hospital discharge in the Northeast as compared to 41 patients in the South). Further research should examine closely the impact of hospital region on survival in trauma patients.

Financial coverage status was also significantly associated with survival. When compared to self-payment or uninsured, all other methods of coverage were positively associated with survival. The available literature reports contradicting findings on financial coverage and association with survival in trauma patients. Greene et al. concluded that insurance status was a predictor of outcome with uninsured patients being at higher risk of death in both blunt and penetrating trauma [34] while Lober et al. [21] noted better survival in patients with no insurance coverage attributing this finding to potentially larger proportion of healthy patients in the uninsured group. In this study of traumatic arrests any insurance status (compared to uninsured) was associated with improved outcomes. Further research is needed to clarify the reasons for this disparity such as examining resources utilization including but not limited to access to surgical procedures.

This study has potential limitations related to its retrospective nature and to availability of data reported in the database. The NTDB uses ICD-9 coding for the data retrieved from different hospitals and is like other national databases subject to coding variations and errors. This study did not include traumatic arrests that were not transported to a trauma center which might have led to overestimation of the survival rate in this group of patients. The NTDB also uses "convenience samples" from disproportionate number of large to small hospitals that contribute to the database. This unequal sample size across regions and the lack of weighting should be taken into considerations when comparing outcomes across different US regions. Another limitation is related to absence of NTDB of important clinical factors (no-flow time, low-flow time) which have been shown to be important predictors of survival. Adding these data elements to trauma registries can improve future trauma studies examining outcomes.

Despite these limitations, the NTDB is the largest database for trauma in the United States of America collecting data from over 900 hospitals and the study findings can be generalized to hospitals in the US and to other settings with similar trauma systems. This study also is comprehensive in examining a heterogeneous sample of traumatic arrests that is reflective of Traumatic arrests treated in different trauma centers in the US. The findings of this study are also important for physicians managing trauma patients in the US and in other areas of the world and familiarity with the identified predictors can allow for better assessment of prognosis when treating traumatic arrests.

\section{Conclusion}

Patients with traumatic arrests continue to have poor outcomes with only $11.1 \%$ surviving to hospital discharge. Several factors were identified to be positively associated with survival in this population. Survival is higher for younger age group, female gender and with any type of insurance coverage. Patients with traumatic arrests from firearm mechanisms experience poor survival. These findings are important for future studies examining closely different predictors, and for devising injury prevention strategies. More evidence is needed to guide trauma management protocols and initiation of resuscitation to improve outcomes further in traumatic arrests.

\section{Acknowledgements \\ Not applicable.}

\section{Authors' contributions}

Dr. El Sayed conceptualized the study, provided insights into the discussion section and contributed to the write-up and editing of the manuscript. Ms. Rana Bachir was the lead statistician of this study, provided insight in data interpretation as well as contributing to the write up. Dr. Ariss carried out the literature reviews, provided insights into the discussion section and contributed the write up of the manuscript. The author(s) read and approved the final manuscript.

Funding

Not applicable.

\section{Availability of data and materials}

The datasets generated and/or analyzed during the current study are available in the National Trauma Data Bank (collected in 2015 and released in 2017) repository: https://www.facs.org/quality-programs/trauma/tqp/ center-programs/ntdb.

\section{Declarations}

Ethics approval and consent to participate

An Institutional Review Board Exemption was obtained at the American University Of Beirut. No consent was obtained since the data was retrieved from a de-identified database i.e. NTDB (National Trauma Data Bank).

Consent for publication

Not applicable.

Competing interests

All authors have declared that they have no financial conflict of interest.

Received: 20 November 2020 Accepted: 23 June 2021

Published online: 05 July 2021

References

1. World Health Organization. Injuries and violence: the facts. https://www. who.int/violence_injury_prevention/media/news/2015/Injury_violence_fa cts_2014/en/. Accessed 10 Jan 2019. 
2. Rhee P, Joseph B, Pandit V, Aziz H, Vercruysse G, Kulvatunyou N, Friese RS. Increasing trauma deaths in the United States. Ann Surg. 2014;260:13-21.

3. Shimazu S, Shatney $\mathrm{CH}$. Outcomes of trauma patients with no vital signs on hospital admission. J Trauma. 1983:23:213-6.

4. Battistella FD, Nugent W, Owings JT, Anderson JT. Field triage of the pulseless trauma patient. Arch Surg. 1999;134:742-5; discussion 745-6.

5. Ahmed N, Greenberg P, Johnson VM, Davis JM. Risk stratification of survival in injured patients with cardiopulmonary resuscitation within the first hour of arrival to trauma centre: retrospective analysis from the national trauma data bank. Emerg Med J. 2017;34:282-8.

6. Hopson LR, Hirsh E, Delgado J, Domeier RM, McSwain NE Jr, Krohmer J, National Association of EMS Physicians Standards and Clinical Practice Committee, American College of Surgeons Committee on Trauma. Guidelines for withholding or termination of resuscitation in prehospital traumatic cardiopulmonary arrest: a joint position paper from the National Association of EMS Physicians Standards and Clinical Practice Committee and the American College of Surgeons Committee on Trauma. Prehosp Emerg Care. 2003;7:141-6.

7. National Association of EMS Physicians, American College of Surgeons Committee on Trauma. Withholding of resuscitation for adult traumatic cardiopulmonary arrest. Prehosp Emerg Care. 2013;17:291.

8. Kleber C, Giesecke MT, Lindner T, Haas NP, Buschmann CT. Requirement for a structured algorithm in cardiac arrest following major trauma: epidemiology, management errors, and preventability of traumatic deaths in Berlin. Resuscitation. 2014;85:405-10.

9. Moore HB, Moore EE, Burlew CC, Biffl WL, Pieracci FM, Barnett CC, Bensard DD, Jurkovich GJ, Fox CJ, Sauaia A. Establishing benchmarks for resuscitation of traumatic circulatory arrest: success-to-rescue and survival among 1708 patients. J Am Coll Surg. 2016;223:42-50.

10. Lai $\mathrm{C}-\mathrm{Y}$, Tsai $\mathrm{S}-\mathrm{H}$, Lin $\mathrm{F}-\mathrm{H}$, et al. Survival rate variation among different types of hospitalized traumatic cardiac arrest: a retrospective and nationwide study. Medicine (Baltimore). 2018;97:e11480.

11. Djarv T, Axelsson C, Herlitz J, Stromsoe A, Israelsson J, Claesson A. Traumatic cardiac arrest in Sweden 1990-2016 - a population-based national cohort study. Scand J Trauma Resusc Emerg Med. 2018. https://doi.org/10.1186/s13 049-018-0500-7.

12. Huber-Wagner S, Lefering R, Qvick M, Kay MV, Paffrath T, Mutschler W, Kanz K-G, Working Group on Polytrauma of the German Trauma Society (DGU). Outcome in 757 severely injured patients with traumatic cardiorespiratory arrest. Resuscitation. 2007;75:276-85.

13. Chen Y-C, Wu K-H, Hsiao K-Y, Hung M-S, Lai Y-C, Chen Y-S, Chang C-Y. Factors associated with outcomes in traumatic cardiac arrest patients without prehospital return of spontaneous circulation. Injury. 2019;50:4-9.

14. American College of Surgeons Committee on Trauma. (2015). ACS NTDB National Trauma Data Standard: Data Dictionary (2016 Admissions).

15. Boyd CR, Tolson MA, Copes WS. Evaluating trauma care: the TRISS method. J Trauma. 1987:27:370-8.

16. American College of Surgeons Committee on Trauma. National trauma databank user manual: NTDB research data set admission year 2006-2015. Chicago: American College of Surgeons; 2015.

17. Hicks CW, Hashmi ZG, Velopulos C. Association between race and age in survival after trauma. JAMA Surg. 2014;149:642. https://doi.org/10.1001/jama surg.2014.166.

18. Pickens JJ, Copass MK, Bulger EM. Trauma patients receiving CPR: predictors of survival. J Trauma. 2005:58:951-8

19. Tisherman SA. Salvage techniques in traumatic cardiac arrest: thoracotomy, extracorporeal life support, and therapeutic hypothermia. Curr Opin Crit Care. 2013;19(6):594-8

20. Crewdson K, Lockey D. Mortality in traumatic cardiac arrest. Resuscitation. 2017;113:e21.

21. Loberg JA, Hayward RD, Fessler M, Edhayan E. Associations of race, mechanism of injury, and neighborhood poverty with in-hospital mortality from trauma: a population-based study in the Detroit metropolitan area. Medicine (Baltimore). 2018;97:e12606.

22. Pape M, Giannakópoulos GF, Zuidema WP, et al. Is there an association between female gender and outcome in severe trauma? A multi-center analysis in the Netherlands. Scand J Trauma Resusc Emerg Med. 2019;27:16

23. Barnard E, Yates D, Edwards A, Fragoso-Iñiguez M, Jenks T, Smith JE. Epidemiology and aetiology of traumatic cardiac arrest in England and Wales - a retrospective database analysis. Resuscitation. 2017;110:90-4.
24. Beck B, Bray JE, Cameron P, Straney L, Andrew E, Bernard S, Smith K. Predicting outcomes in traumatic out-of-hospital cardiac arrest: the relevance of Utstein factors. Emerg Med J. 2017;34:786-92.

25. Stockinger ZT, McSwain NE Jr. Additional evidence in support of withholding or terminating cardiopulmonary resuscitation for trauma patients in the field. J Am Coll Surg. 2004;198:227-31.

26. Evans CCD, Petersen A, Meier EN, Buick JE, Schreiber M, Kannas D, Austin MA. Resuscitation Outcomes Consortium Investigators Prehospital traumatic cardiac arrest: management and outcomes from the resuscitation outcomes consortium epistry-trauma and PROPHET registries. J Trauma Acute Care Surg. 2016:81:285-93.

27. Hoyert DL, Kochanek KD, Murphy SL. Deaths: final data for 1997. Natl Vital Stat Rep. 1999;47:1-104.

28. Burt CW, Fingerhut LA. Injury visits to hospital emergency departments: United States, 1992-95. Vital and Health Statistics. 1998: Series 13, Data from the National Health Survey; no. 131; DHHS publication; no. (PHS) 98-1792.

29. Beaman V, Annest JL, Mercy JA, Kresnow MJ, Pollock DA. Lethality of firearm-related injuries in the United States population. Ann Emerg Med. 2000:35:258-66.

30. Kauvar DS, Lefering $R$, Wade CE. Impact of hemorrhage on trauma outcome: an overview of epidemiology, clinical presentations, and therapeutic considerations. J Trauma. 2006;60:S3-11.

31. The ATLS Subcommittee, American College of Surgeons', Committee on Trauma, and the International ATLS working group. Advanced trauma life support $\left(A T L S^{\oplus}\right)$ : The ninth edition. J Trauma Acute Care Surg. 2013; 74:1363-6.

32. Brown JB, Rosengart MR, Billiar TR, Peitzman AB, Sperry JL. Geographic distribution of trauma centers and injury-related mortality in the United States. J Trauma Acute Care Surg. 2016;80:42-9; discussion 49-50.

33. Branas CC, MacKenzie EJ, Williams JC, Schwab CW, Teter HM, Flanigan MC, Blatt AJ, ReVelle CS. Access to trauma centers in the United States. JAMA. 2005;293:2626-33.

34. Greene WR, Oyetunji TA, Bowers U, Haider AH, Mellman TA, Cornwell EE, Siram SM, Chang DC. Insurance status is a potent predictor of outcomes in both blunt and penetrating trauma. Am J Surg. 2010;199:554-7.

\section{Publisher's Note}

Springer Nature remains neutral with regard to jurisdictional claims in published maps and institutional affiliations.

\section{Ready to submit your research? Choose BMC and benefit from:}

- fast, convenient online submission

- thorough peer review by experienced researchers in your field

- rapid publication on acceptance

- support for research data, including large and complex data types

- gold Open Access which fosters wider collaboration and increased citations

- maximum visibility for your research: over $100 \mathrm{M}$ website views per year

At BMC, research is always in progress.

Learn more biomedcentral.com/submissions 